\title{
Study The Rate Constant of Photodecomposition of Polystyrene Films in Presence of Some 4- amino-5-(2-(6-methoxynaphthalen-2-yl)piperidino)-1,2,4- triazole-3-thion Complexes
}

\author{
Adil A. Awad *, Rehab A. M. Al-Hasani ${ }^{*}$ and Emad A. Yousif ${ }^{* *}$ \\ * Department of Chemistry, College of Science, Al-Mustansirya University, Baghdad-Iraq. \\ ** Department of Chemistry, College of Science, Al-Nahrain University, Baghdad-Iraq.
}

\begin{abstract}
The photostabilization of polystyrene (PS) films by (4-amino-5-(2-(6-methoxynaphthalen-2yl)piperidino)-1,2,4-triazole-3-thion(L) compounds was investigated. PS films containing concentration of complexes $0.5 \%$ by weight were produced by the casting method from chloroform as a solvent. The photostabilization activities of these compounds were determined by monitoring the carbonyl and hydroxyl indices with irradiation time. The photostabilization of PS films by prepared complexes was investigated. The PS films containing concentration of complexes $0.5 \%$ by weight were produced by the casting method from $\left(\mathrm{CHCl}_{3}\right)$ solvent. The photodegradation of the obtained films was investigated using UV-vis. spectra. The photostabilization activity of these compounds was determined by calculating the photodecomposition rate constant $(k \mathrm{~d})$ for the modified PS.
\end{abstract}

Keyword: Photochemistry, polystyrene, Photostabilizer, UV Absorber.

\section{Introduction}

Triazoles are five memberd heterocyclic compounds containing three nitrogen and two carbon atoms. The substituted triazole with sulphur atom and amine group are considered to be good coordinating ligands because they involved both hard nitrogen and soft sulfur atom as thio amide group, this ligand have doner group that coordinate with wide range of metal ions [1,2]. In this paper some complexes of substituted 1,2,4 triazol with thio and amino group has been used as photostabilizer for polystyrene. The low cost and the good performance of PS products have increased the utilization of this polymer in building and other application, it is a multipurpose polymer that is used in varied applications include rigid item. General purpose polystyrene is clear and hard which is used in packaging, laboratory ware, and electronics [3]. One of the important uses of PS is in the manufacture of cover signal lamps of some automobiles [4,5]. The photooxidative degradation processes of PS have been discussed in a number of reviews [6,7]. It is generally accepted that carbonyl formed during UV irradiation of polymers, is most probable and are responsible for the yellow coloration of the polymer [8].

The carbonyl groups generated during the photooxidation process of polymer, extend the polymer film absorption to longer wavelengths. These groups absorb light when they irradiated with light of wavelength between (200-700 nm) and activated to the singlet and triplet excited states which enhances various successive photooxidation reactions [9]. The physical properties of additives and polymers play a very important role in determining the additives efficiency in photostabilization or photodegradation of polymers. For example, the compatibility that any type of additive (photostabilizer, antioxidant, thermal stabilizer.... etc.) must be evenly distributed which requires that it be compatible with the polymer matrix [10]. In this paper we report the prepared chelates were used to enhance the photostabilization Polymer (PS). Polymer has been mixed with these complexes in solvent which containing concentration of complex $0.5 \%$ by weight, which produced by the casting method from $\mathrm{CHCl}_{3}$ solvent. The photostabilization of polymer films were studied at room temperature under irradiation of light $\lambda=365$ $\mathrm{nm}$ wave length with intensity $6.02 * 10^{-9}$ Ein $\mathrm{Dm}^{-3} \mathrm{~S}^{-1}$. In the present study, we report $\mathrm{kd}$ values to investigate the activity of the prepared complexes as photostabilizers against UV light in the PS polymer films. 


\section{Experimental}

\section{Materials and Methods}

All the reagents, starting materials as well as solvents were purchased commercially and used without any further purification. The ultraviolet-visible (UV-VIS) spectra were recorded by using Shimadzu UV-VIS. 160 AUltra-violet spectrophotometer in the range of 200-1100 nm. [4-amino-5-(2-(6methoxynaphthalen-2-yl)piperidino)-1,2,4triazole-3-thion and matel complexes was prepared by the method previously described [11] as in Fig.(1).

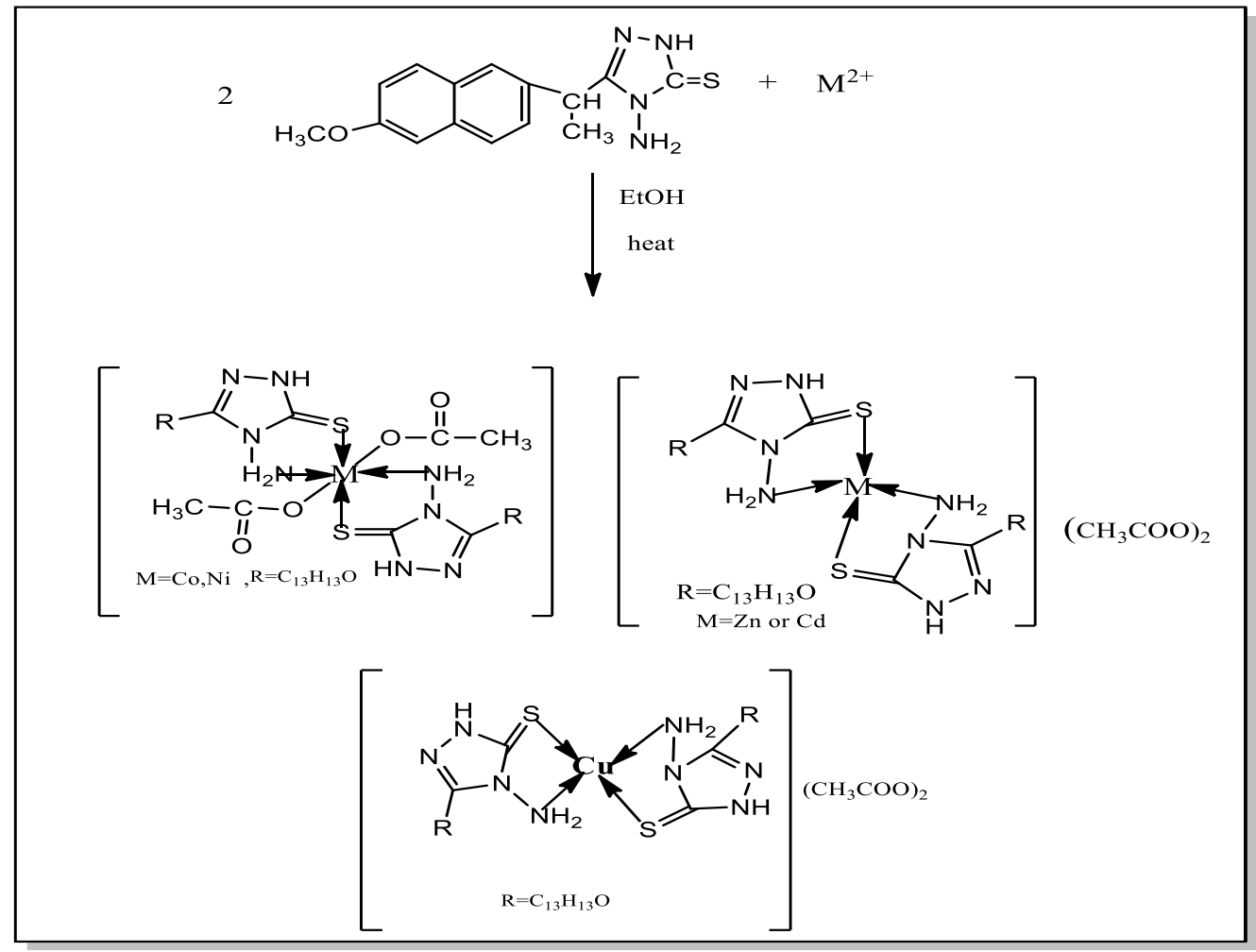

Fig.(1): The Synthetic route of the metal complexes derived from ligand.

\section{Experimental Techniques Film preparation}

PS dissolved with metal complexes in $\mathrm{CHCl}_{3}$ solvent to form PS films of $5 \%(40 \mu \mathrm{m})$ thickness containing concentrations of the complex by weight. Their thickness was measured by a micrometer type 2610 A, Germany. The films were prepared by evaporation technique at room temperature for 24 hours, to remove the possible residual solvent [12].

\section{Irradiation experiment}

\section{Accelerated testing technique}

UV- Light lamp was used for irradiation of Polymer films, giving wavelength range between ( 250 to $380 \mathrm{~nm}$ ) and the maximum wavelength light intensity is at $6.2 \times 10^{-9}$ Ein $\mathrm{Dm}^{-3} \mathrm{~S}^{-1}$. The polymer film samples were fixed parallel to each other and the lamp of the UV. incident radiation is vertically incident on the samples. The distance between the polymer films and the source was $(10 \mathrm{~cm})$. The irradiated samples were rotated from time to time to ensure that the intensity of light incident on all samples is the same [13]. 
Photodegradation measuring methods Measuring the Photodegradation Rate of Polymer Films Using Ultraviolet-Visible Spectrophotometer

The ultraviolet-visible spectrophotometer type Shimadzu UV-VIS. 160 was used to measure the changes in the UV-visible spectrum during irradiation time for each compound at maximum absorption band $\left(\lambda_{\max }\right)$. The absorption spectrum was measured in the range of $(200-400 \mathrm{~nm})$, and the $\left(\lambda_{\max }\right)$ at each absorption was also recorded for different irradiation times.

The infinite irradiation time was considered and the infinite absorption $\left(\mathrm{A}_{\infty}\right)$ was assumed to be after the infinite irradiation time. To determine the photodegradation rate constant for photostabilizer $\left(\mathrm{K}_{\mathrm{d}}\right)$, the first order equation was used:

$\ln (\mathrm{a}-\mathrm{x})=\ln \mathrm{a}-\mathrm{K}_{\mathrm{d}} \mathrm{t}$

Where "a" represents the stabilizer concentration before irradiation and " $x$ " represents the change in stabilizer concentration after irradiation time $(\mathrm{t})$. If $\mathrm{A}_{\mathrm{o}}$ represents the absorption intensity of the polymer film containing stabilizer before irradiation and $A_{t}$ represents the absorption intensity after $t$ time of irradiation, then:

$\mathrm{a}=\mathrm{A}_{0}-\mathrm{A}_{\infty}$

$\mathrm{x}=\mathrm{A}_{\mathrm{o}}-\mathrm{A}_{\mathrm{t}}$

$a-x=A_{o}-A_{\infty}-A_{o}+A_{t}=A_{t}-A_{\infty}$

Substitution of $\mathrm{a}$ and $(\mathrm{a}-\mathrm{x})$ from equation (3) in (2) gives:

$\ln \left(A_{t}-A_{\infty}\right)=\ln \left(A_{o}-A_{\infty}\right)-K_{d} t$

Thus a plot of $\ln \left(A_{t}-A_{\infty}\right)$ versus irradiation time $(\mathrm{t})$ gives straight line with a slope equal $\left(\mathrm{K}_{\mathrm{d}}\right)$ which indicates that photodecomposition of the additives is first order.

\section{Results and Discussion}

\section{Ultra-violet spectral studies of photodegradation rate of in PS films}

The photooxidative degradation processes of PS have been discussed in a number of reviews $[6,14]$. It is generally accepted that carbonyl formed during UV irradiation of polymers, is most probable and are responsible for the yellow coloration of the polymer [7].
The carbonyl groups generated during the photooxidation process of polymer, extend the polymer film absorption to longer wavelengths $[9,15]$. These groups absorb light when they irradiated with light of wavelength between $(200-700 \mathrm{~nm})$ and activated to the singlet and triplet excited states which enhances various successive photooxidation reactions [9].

The physical properties of additives and polymers play a very important role in determining the additives efficiency in photostabilization or photodegradation of polymers. For example, the compatibility that any type of additive (photostabilizer, antioxidant, thermal stabilizer.... etc.) must be evenly distributed which requires that it be compatible with the polymer matrix $[10,16]$. The additives used in this study were chosen to be completely soluble in polymer solvent (Cloroform).

It has been notice that the additives used in the present work are photodecomposed during the photolysis. Thus the photo decomposition rate constant $\left(\mathrm{K}_{\mathrm{d}}\right)$ was calculated. The $\mathrm{K}_{\mathrm{d}}$ values were computed using the UV. spectra changes of PS films thickness $40 \mu \mathrm{m}$ containing $0.5 \%$ from additives. The plot of irradiation time versus $\ln \left(\mathrm{A}_{\mathrm{t}}-\mathrm{A}_{\mathrm{\alpha}}\right)$, gives straight line which indicate primarily the first order reaction. The slope equal to the decomposition rate constant $\mathrm{K}_{\mathrm{d}}$. Fig.(2) to (7) shows the variation of $\ln \left(\mathrm{A}_{t}-\mathrm{A}_{\alpha}\right)$ with irradiation time for all additives in PS films at $\lambda=365 \mathrm{~nm}$. 
Adil A. Awad

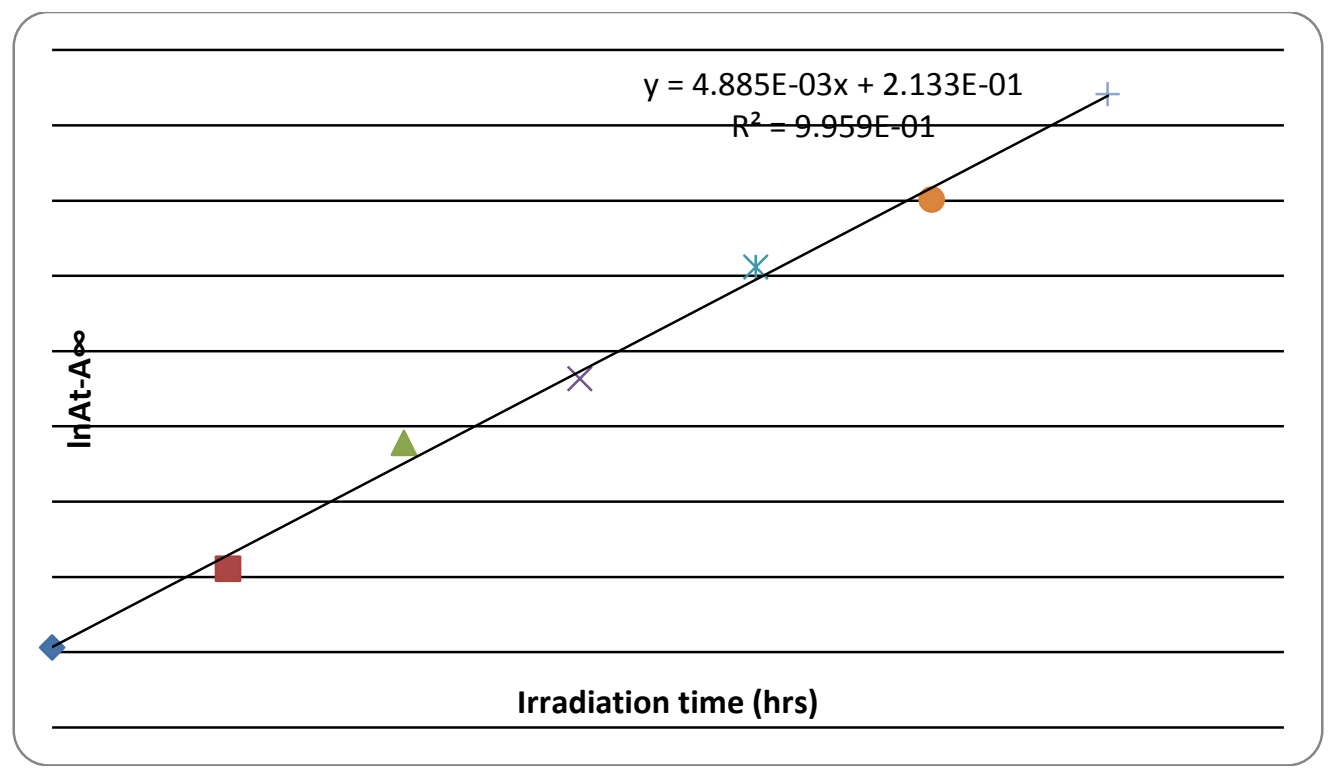

Fig.(2): Variation of natural logarithm of $\ln \left(A_{t}-A_{\infty}\right)$ with irradiation time of PS (blank) film.

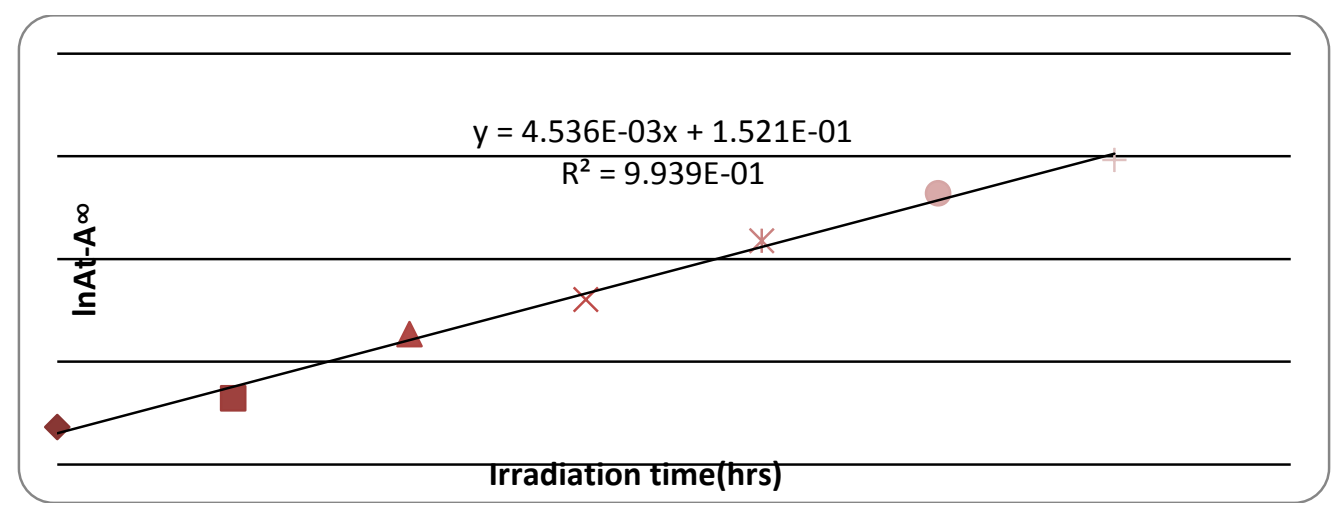

Fig.(3): Variation of natural logarithm of $\ln \left(A_{t}-A_{\infty}\right)$ with irradiation time of $(L)$ in PS film.

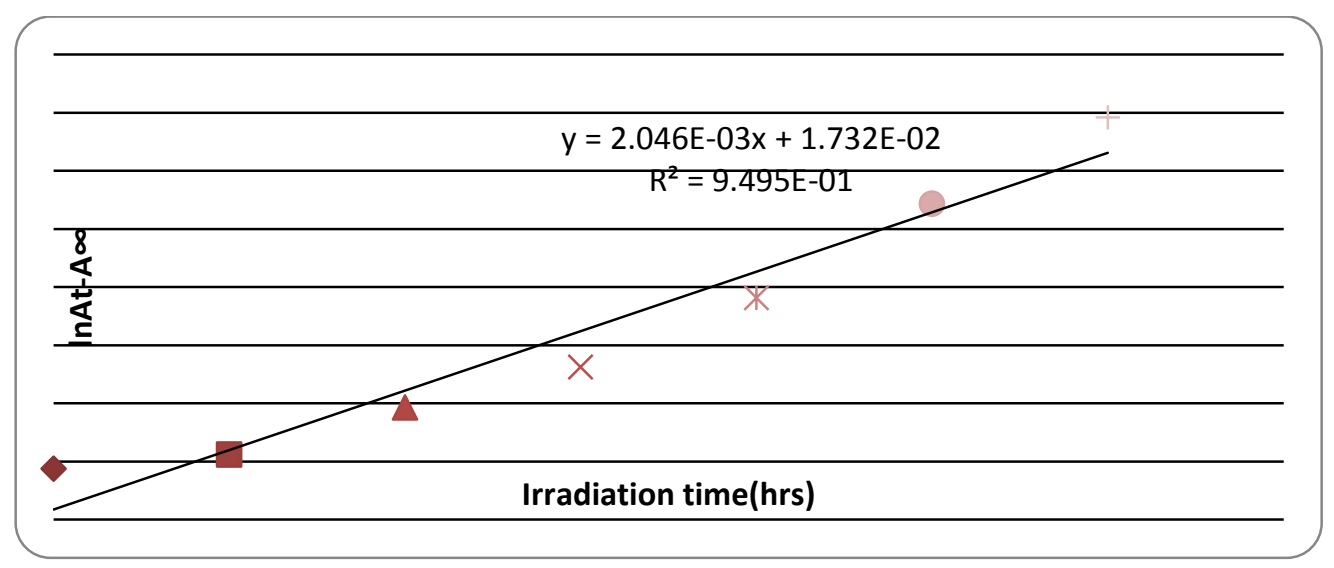

Fig.(4): Variation of natural logarithm of $\ln \left(A_{t}-A_{\infty}\right)$ with irradiation time of $\left(A_{I}\right)$ in PS film. 


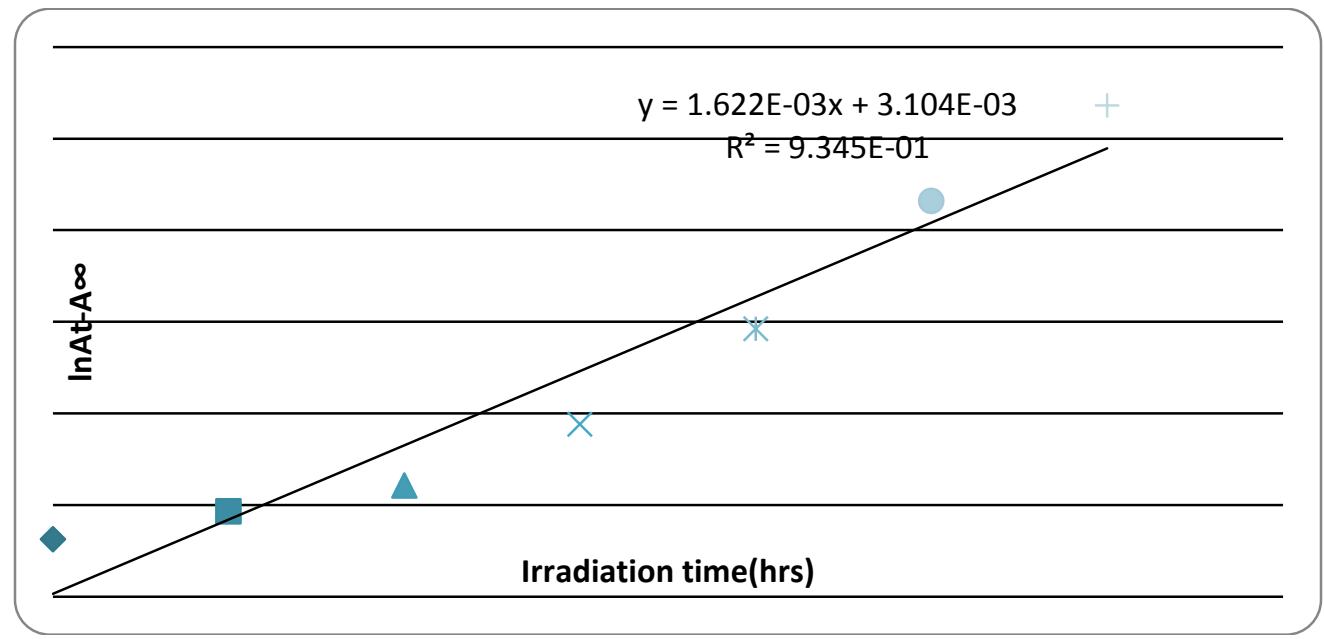

Fig.(5): Variation of natural logarithm of $\ln \left(A_{t}-A_{\infty}\right)$ with irradiation time of $\left(A_{2}\right)$ in PS film.

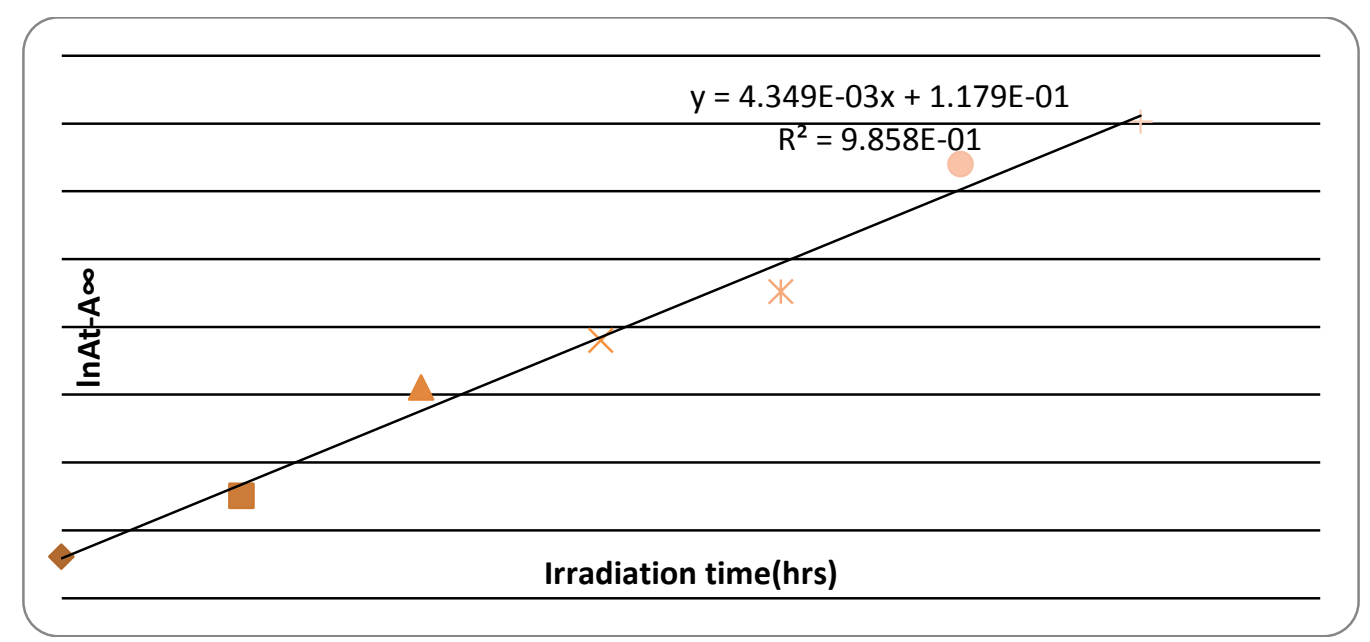

Fig. (6): Variation of natural logarithm of $\ln \left(A_{t}-A_{\infty}\right)$ with irradiation time of $\left(A_{3}\right)$ in PS film.

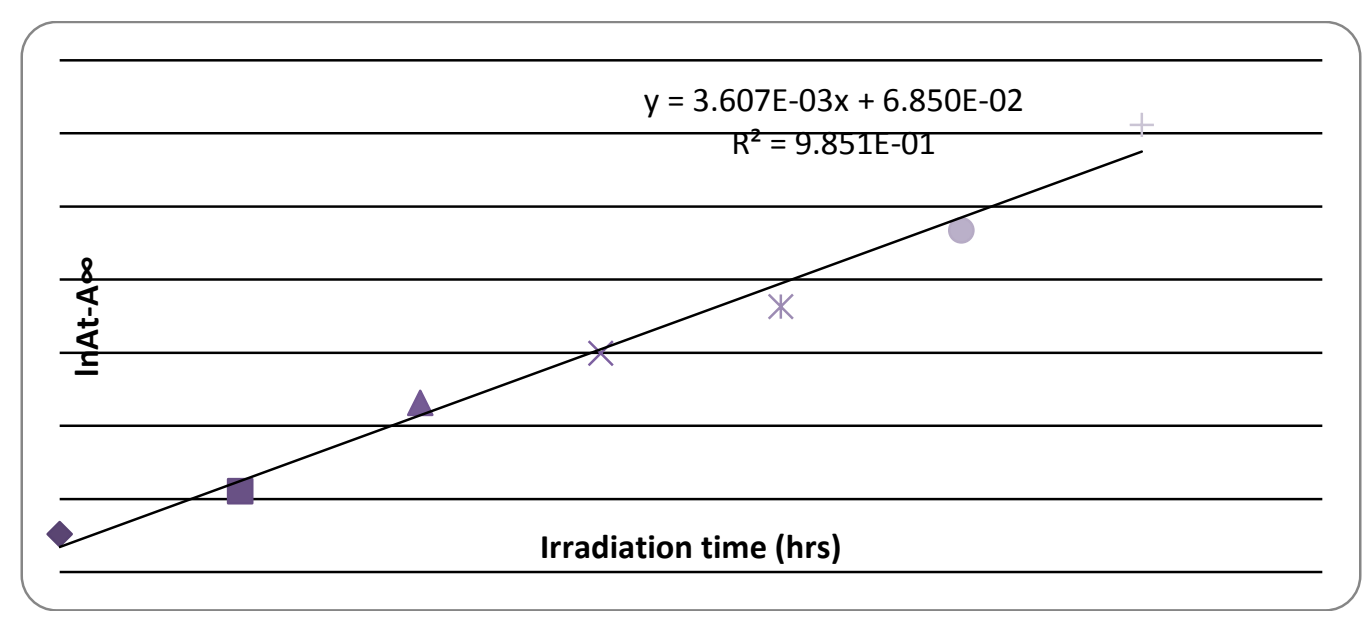

Fig.(7): Variation of natural logarithm of $\ln \left(A_{t}-A_{\infty}\right)$ with irradiation time of $\left(A_{4}\right)$ in PS film. 


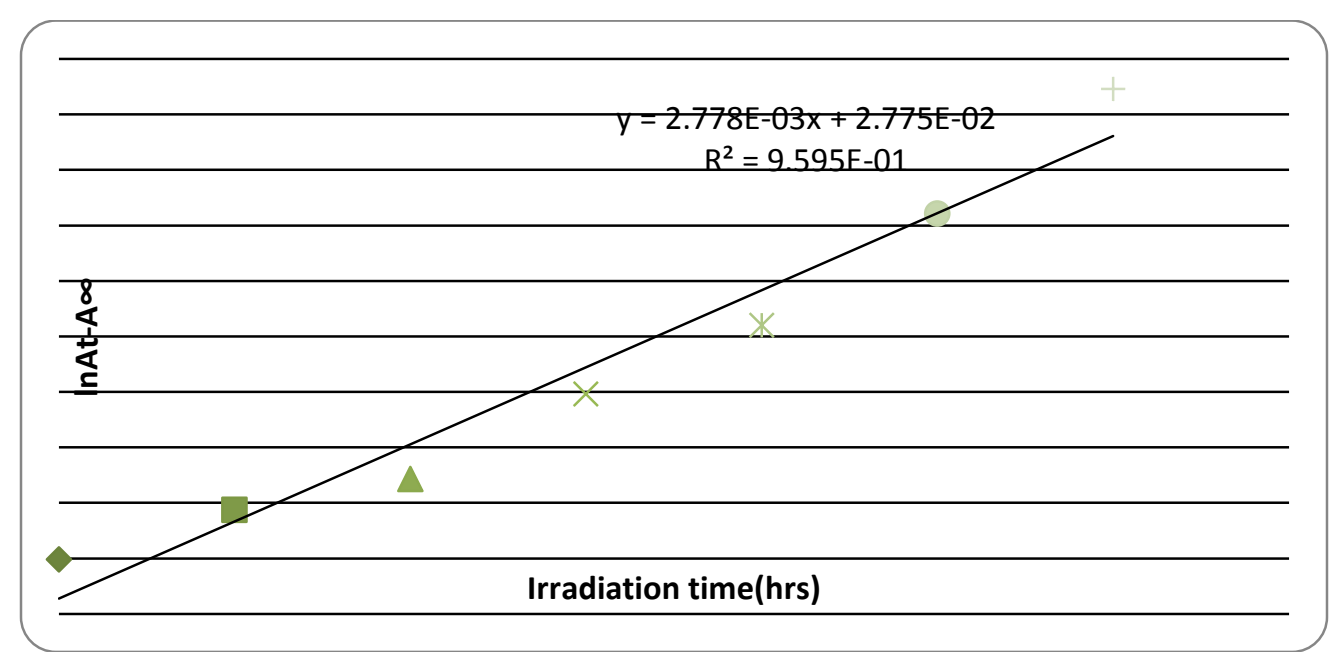

Fig.(8): Variation of natural logarithm of $\ln \left(A_{t}-A_{\infty}\right)$ with irradiation time of $\left(A_{5}\right)$ in PS film.

The values of the first order rate constant of all the modified polymers films $\left(\mathrm{k}_{\mathrm{d}}\right)$ calculated by the same way and shown in Table (1).

\section{Table (1)}

Photodecomposition rate constant $\left(K_{d}\right)$ of PS films thickness (40 $\mathrm{\mu m}$ ) containing $0.5 \%$ of additives.

\begin{tabular}{||c|c||}
\hline Compounds & $\boldsymbol{K}_{\boldsymbol{d}}\left(\boldsymbol{S}^{-1}\right)$ \\
\hline \hline PS (blank) & $4.885 * 10^{-3}$ \\
\hline \hline $\mathrm{PS}+\mathrm{L}$ & $4.536 * 10^{-3}$ \\
\hline \hline $\mathrm{PS}+\left(\mathrm{A}_{3}\right)$ & $4.349 * 10^{-3}$ \\
\hline $\mathrm{PS}+\left(\mathrm{A}_{4}\right)$ & $3.607 * 10^{-3}$ \\
\hline $\mathrm{PS}+\left(\mathrm{A}_{5}\right)$ & $2.778 * 10^{-3}$ \\
\hline $\mathrm{PS}+\left(\mathrm{A}_{1}\right)$ & $2.046 * 10^{-3}$ \\
\hline $\mathrm{PS}+\left(\mathrm{A}_{2}\right)$ & $1.622 * 10^{-3}$ \\
\hline
\end{tabular}

The photostabilizers always posses low $\mathrm{K}_{\mathrm{d}}$ values, which mean that these modified polymers are stable towards UV light. One could notice that $\mathrm{K}_{\mathrm{d}}$ values are sensitive to the type of additives in PS films, which decrease in the following order:

PS $>$ L(II) $\left(\right.$ A3 $\left._{3}\right)>\left(\right.$ A4 $\left._{4}\right)>\left(\right.$ Af $\left._{5}\right)>\left(\right.$ A1 $\left._{1}\right)>\left(\right.$ A $\left._{2}\right)$ and this might point out to increase the photostability of this additives in this term.

\section{Conclusion}

Addition of the complexes (4- amino-5-(2(6-methoxynaphthalen-2-yl)piperidino)-1,2,4triazole-3-thion (L) to PS films have successfully worked as photoinducer for degradation process for PS films. The photostabilization of PS films were investigated. The additives take the following order in photostabilization activity according to their decrease in rate constant.

\section{Acknowledgements}

The authors acknowledge Al- Mustansiriya University and Al-Nahrain University for their encouragement.

\section{References}

[1] Al-Maydama H., Al-Ansi T., Jamil Y., and Ali A., Biheterocyclic ligands: Synthesis, characterization and coordinating properties of bis(4-amino-5-mercapto-1,2,4-triazol-3yl) alkanes with transition metal ions and their thermokinetic and biological studies. Ecl.Quim., 33(3), 29-42, 2008.

[2] Narayana B., and Gajendragad M., Complexes of $\mathrm{Zn}(\mathrm{II}), \mathrm{Pd}(\mathrm{II}), \mathrm{Hg}(\mathrm{II}), \mathrm{Pb}(\mathrm{II})$, $\mathrm{Cu}(\mathrm{I}), \operatorname{Ag}(\mathrm{I})$, and $\mathrm{Ti}(\mathrm{I})$ with 4-amino-5merccapto-3-(otolyloxymethyl)-1,2,4-

troazol. Tr. J. of chemistry Tur. J. Chem., 21, 71-76, 1997.

[3] Meenakshi P., Noorjahan E., Rajini, R., Venkateswarlu, U., and Crose S., Mechanicaland microstructure studies on the modification of $\mathrm{CA}$ film by blending with Polystyrene. Indian Academy of Sciences. 25(1), 25-29, 2002.

[4] Safy Eldin M. and El-laithy A., Photooxidative degradation of polystyrene of cover signals lamp of some automobile, Journal of applied Polymer Science. 55: 47$54,1994$. 
[5] Atiq N., Biodegradability of Synthetic Plastics Polystyrene and Styrofoam by Fungal Isolates, $\mathrm{Ph}$ D. thesis. 2011.

[6] Rabek J., Ranby b., Studies on the photooxidation mechanism of polymers. II. The role of quinones as sensitizers in the photooxidative degradation of polystyrene. J. of Polymer Sci. 2(2), 295-306, 2003.

[7] Lawrence J., and Weir N., Photodecomposition of polystyrene on long-wave ultraviolet irradiation: A possible mechanism of initiation of photooxidation. J. Polym. Sci. 11(1): 105118, 2003.

[8] Mori F., Koyama M., and Oki Y., Physical Properties of Polymers Handbook. Angew. Makromol. Chem., 75, 113-122, 1979.

[9] Cooray B. and Scott G., Polymer Photodegradation: Mechanisms and Experimental Methods. J. Eur. Polym. 169(16), 177-189, 1980.

[10] Gugumns F., Development in polymer photostabilization-1, (G. Scott, ed.), Applied Science Publisher Ltd, London, 261-272, 1979.

[11] Adil A., Rehab A., Yousif E., Synthesis Characterization and Antimicrobial Studies of(4- amino-5-(2-(6-methoxynaphthalen-2yl)piperidino)-1,2,4-triazole-3-thion with $\mathrm{Co}(\mathrm{II}), \mathrm{Ni}(\mathrm{II}), \mathrm{Cu}(\mathrm{II}), \mathrm{Zn}(\mathrm{II})$ and $\mathrm{Cd}(\mathrm{II})$ matel ions, J. Iraqi Industrial Res., 2 (2), 19, 2015.

[12] Diepens M., Photodegradation and Stability of Bisphenol, A Polycarbonate in Weathering Conditions, Enschede, The Netherlands. 2009.

[13]. Yousif E., Salimon J., Salih N., New stabilizer for polystyrene based on $2-\mathrm{N}$ Salicylidene-5-(substituted)-1,3,4thiadiazole compoundes, J. Saudia. Chem. Soc., 16(3): 299-306, 2011.

[14] Haddad R., and Rahimim Y., Ultra Violet Spectra Studies of Polystyrene Films in Presence of Some Transition Metal Complexes with4-amino-5-pyridyl)-4h1,2,4-triazole-3-thiol, Orie. J. Chem, 31 (1):591-596, 2015.

[15] Yousif E., Salimon J., Salih N., New photostabilizers for PVC based on some diorganotin (IV) complexes., J. Saudi Chem. Soc, 19:133-141, 2015.
[16] Asim A., Balakit., Ahmed A., Gamal A., El-Hiti., Keith Smith., and Yousif E., Synthesis of New Thiophene Derivatives and Their Use as Photostabilizers for Rigid Poly (vinyl chloride), International J. of Polymer Science, Article ID 510390, 1-10, 2015.

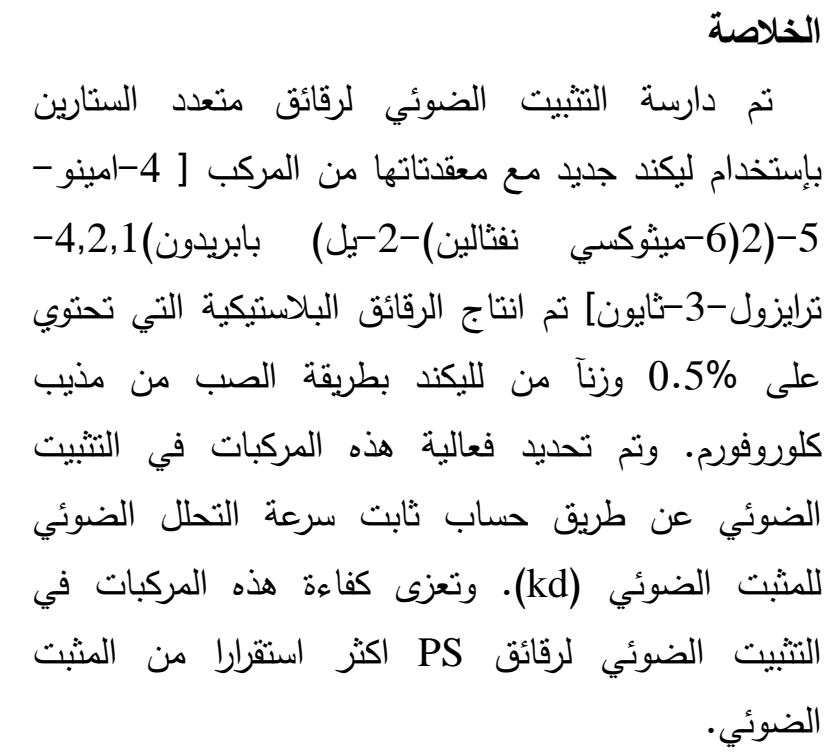

